\title{
"Super-Meninas em: o poder do rosa!?!" Por uma compreensão das feminilidades infantis a partir dos estudos de mídia, gênero e infância
}

\author{
Juliane Di Paula Queiroz Odinino*
}

\section{Resumo}

O presente artigo problematiza o lugar social e cultural da menina, no contexto da cultura midiática globalizada. $\mathrm{O}$ recorte analítico remete à pesquisas realizadas com crianças de séries iniciais, da regiáo da grande Florianópolis, em seus contextos escolares e da presença de referenciais identitários que culminam na imagem da que denominamos Menina-Super-Poder-Rosa. A análise dialoga, tensiona e questiona tal representação, cujos significados são marcados pela sua inerente ambiguidade e contradição, sobretudo quando apropriados e ressiginificados pelas crianças. Tal imagem congrega elementos e caraterísticas que se voltam a uma espécie de feminilidade infantil contemporânea, onde é possível constatar matrizes culturais mais tradicionais. Nesse sentido, figuram aspectos ligados à passividade e à subserviência feminina ao lado de características mais atuais relacionadas às conquistas feministas e ao empoderamento das mulheres. Para a realização da pesquisa com as crianças, fez-se uso da etnografia e da pesquisa-intervenção com o propósito de problematizar as relaçôes de poder, principalmente as voltadas às questóes de gênero, infância e mídia. Como resultado, notou-se que as feminilidades infantis por mais que tenham avançado rumo à igualdade de direitos e à liberdade de expressão, ainda continuam ocupando um lugar de subalternidade, de inferiorização e de naturalizaçáo das diferenças, sendo cristalizadas em práticas sexistas e discriminátorias, as quais são vivenciadas e reproduzidas cotidiadianamente nas interrelaçôes infantis.

Palavras-chave: Mídia. Gênero. Infância.

* Doutora em Ciências Humanas pela Universidade Federal de Santa Catarina (UFSC). Professora do curso de Pedagogia da Faculdade Municipal de Palhoça (FMP). 
O objetivo deste artigo consiste em problematizar o lugar social e cultural das meninas, a partir da imagem da menina-super-poder-rosa, presentificado no imaginário cultural de massa e partilhado nas vivências e brincadeiras de meninas das séries iniciais, em seus contextos escolares, conforme observado em pesquisas com crianças realizadas pela autora na região da grande Florianópolis.

A escola foi escolhida como lócus de pesquisa sobre cultura(s) da(s) infância(s) por se constituir enquanto espaço privilegiado de consolidaçáo do coletivo infantil nos espaços urbanos. Soma-se a isso o papel da cultura midiática e global para o delineamento das identidades infantis na contemporaneidade. Ainda neste recorte vêm à tona reflexôes acerca das interseccionalidades de gênero, de feminilidades, de consumismo e de diversidade cultural que interpenetram, assentam e recombinam-se enquanto elementos constituientes das culturas infantis.

Como pesquisa empírica, fruto das experiências do doutorado (2009) e do pósdoutorado em andamento (2014-2015), serão descritas e analisadas algumas situaçôes vivenciadas junto às crianças a partir da realização de pesquisa etnográfica e de intervençáo, que igualmente lançam luz sobre aspectos referentes à metodologia de pesquisa com crianças relacionada, em especial, aos estudos de gênero, de mídia e de infância. Os grupos de crianças interlocutoras em ambos momentos apresentavam, apesar da diferença anacrônica/temporal, algumas características iguais: serem estudantes de primeiros anos do turno vespertino, com idade entre seis e sete anos na época da pesquisa e provenientes de escolas públicas da regiâo da grande Florianópolis.

Nessas experiências, procuramos uma compreensão das culturas infantis vivenciadas especialmente em seus denomimados momentos livres, segundo definição das próprias crianças. Esses aconteceriam em determinados tempos-espaços da escola, como nos intervalos, nas entradas e saídas, na proposição de atividades lúdicas e no uso das tecnologias disponíveis ${ }^{1}$. Tais expressões reconhecidas como livres foram tomadas pela perspectiva da elaboração de narrativas infantis como constituintes das identidades infantis, tecidas, por sua vez, nas interrelaçóes entre os sujeitos, adultos e crianças em seus contextos escolares. Ora desencadeadas nas brincadeiras e nas experiências lúdicas, ora vivenciadas por meio da proposição de construção de narrativas audiovisuais a partir dos recursos tecnológicos disponíveis como filmadoras, laptops ou tablets.

O recorte teórico-metodológico deste artigo relaciona-se, especialmente, com o modo como as feminilidades e as culturas infantis foram vivenciadas, tendo em vista a constatação da presença de uma matriz cultural fruto dos processos de globalização das culturas, sendo desencadeada pelo amplo alcance dos apelos midiáticos. Notamos, num primeiro momento, a presença do modo de representação mais tradicional da menina como dócil, frágil e dependente, ao mesmo tempo em que constatamos um movimento 
de transgressão, agência e empoderamento que dialoga e tensiona este modelo, sendo exaltado por uma espécie de poder inovador caracteristicamente atribuído a uma percepção de "feminino contemporâneo". Essa imagem foi denominada menina-superpoder-rosa e será melhor problematizada adiante, como eixo norteador de nossa análise.

Do ponto de vista da estratégia metodológica junto aos grupos de crianças, caracterizado pelas etapas da etnografia e da pesquisa-intervenção, partimos da identificação, advinda da observação dos momentos livres das crianças, sobretudo na etapa etnográfica, da dicotomização entre as práticas e relaçóes sociais vivenciadas entre meninas e meninos. Ainda que outros referenciais identitários exerçam papel definidor das práticas culturais infantis e das relaçôes de poder, o aspecto das diferenças de gênero constituiu um fator determinante da socialização primária marcada pela segregação sexista dos grupos infantis em todos os contextos pequisados. Também buscamos considerar o modo como transgridem, rompem padróes, resistem e exercem suas agências a partir do intrincado jogo de poder nas quais as crianças estáo diretamente envolvidas. As situaçóes selecionadas do ponto de vista da imagem da menina-superpoder-rosa compóem um conjunto mais amplo de análises sobre as culturas infantis nos contextos das pesquisas realizadas. Porém, as situaçóes presentes neste artigo relacionam-se àquilo que melhor expressa o que foi considerado, a partir da análise mais ampla de observaçóes e constatações, das feminilidades infantis pelo viés das reflexôes oriundas das categorias de gênero, infância e mídia, melhor descritas no decorrer deste texto.

A infância é problematizada a partir de uma tendência inaugurada nas ciências sociais que procura exaltar a vivência dessa etapa pelo viés da ludicidade, da criação, da invenção, da valorização de suas produçóes e de seus saberes (ROCHA, 1999). Já os estudos de gênero lançam máo do questionamento da ordem estabelecida na hierarquização e no enrijecimento das relaçôes e dos papéis sociais. Enquanto categoria de análise, gênero remete às construçôes histórico-culturais tecidas a partir das marcas biológicas entre homens e mulheres (SCOTT, 1995), ainda que não se limitem a essas, tendo em vista que, por ser relacional, implica a incorporação de outras categorias de significação que igualmente atravessam as relaçóes entre os sujeitos, como raça, etnia, geração, classe, entre outras. Quanto às mídias, estas inauguram, por meio da expansão tecnológica, a possibilidade de um imaginário compartilhado em nível global que dissemina visóes e modelos hegemônicos, a partir de suas narrativas. De todo modo, o contexto sociocultural e territorializado tem se configurado como principal dimensão para a apreensão da maneira como tais referentes são apropriados e ressignificados. No entanto, é possível remeter, a seguir, uma visão hegemônica das feminilidades infantis. 


\section{Infância, gênero e mídia: Imagens da menina-super-poder- rosa}

Pois bem, a experiência da infância hoje se situa no contexto da cultura midiática de alcance global, povoada por imagens, sons, signos e sentidos, que, em seu conjunto, fazem referência menos a uma memória que se presta a ganhar forma como uma totalidade coerente e unívoca, tal como as grandes narrativas modernas, e mais se apresentando composta de fragmentos com possibilidade de serem rearranjadas, a mercê das subjetividades individuais, primado da sociedade de consumo. Em busca de uma elucidação das bases que ajudaram a compor tal cultura midiática, o foco encontra-se na problematização de um cenário compreendido como uma arena onde interesses, diferentes discursos e tensốes se entravam. Daí resultam, ainda que de caráter móvel, ambíguo e fluido, as imagens que compóem e dão forma a que denominaremos super-poder-rosas; resistentes no tempo e produto de uma série de transformaçóes desencadeadas, sobretudo, por movimentos sociais femininos contemporâneos. Chamamos de menina-super-poder-rosa devido as suas três principais características: a identidade infantil e feminina figurada na menina; o rosa graças à intensiva presença dessa cor como símbolo culturalmente consagrado como distintivo de gênero; e, finalmente, a denominação super-poder, propositalmente redundante, para exaltar a "conquista" feminina ocorrida nas últimas décadas nos mais diversos espaços e domínios sociais. Além disso, a denominação menina super-poder-rosa funciona como trocadilho em homenagem ao emblema das personagens do desenho animado das Meninas Super-Poderosas (1998), que serão oportunamente melhor descritas e foram analisadas com maior afinco na oportunidade do doutorado (ODININO, 2009).

$\mathrm{Na}$ intersecção de estudos que envolvem mídia, gênero e infância, como locus da pesquisa, fez-se uso de uma estratégia metodológica interdisciplinar que surgiu como uma demanda do próprio objeto de pesquisa. Toda a discussão teórica, bem como as análises empíricas, encontram-se inseridas no corpo do texto, seguindo um raciocínio que pretende apresentar os elementos que dão forma e conteúdo à super-poder-rosa. Constituem, portanto, fragmentos cuja composição e organicidade dizem respeito a um contexto mais amplo, movido pela explosão tecnológica, multiplicação de imagens, intensivo intercâmbio cultural e o papel do local na consolidação dos sentidos e significados.

Importante ressaltar que os meios aqui escolhidos para compô-la ancoram-se em alguns estudos já realizados sobre a representação feminina na atualidade, bem como aqueles outros que se preocupam com o estatuto da criança frente às mídias. Além disso, retomou-se, simultaneamente, algumas reflexóes da pesquisa empírica realizada 
com as três turmas de crianças, do primeiro ano do ensino fundamental, das escolas públicas da região de Florianópolis, entre elas uma de gestão federal e as outras duas estaduais: (a) o Colégio Aplicação (CA) da Universidade Federal de Santa Catarina (UFSC), em Florianópolis, SC; (b) a Escola Básica de São Tarcísio (EBST), São Bonifácio, SC; e (c) o Instituto Estadual de Educação (IEE), região central de Florianópolis, SC. Enfim, a análise foi de encontro à tentativa de composiçáo de uma imagem feminina infantil promovida pelas mídias e conjugada aos estudos de caso realizados envolvendo as crianças nos dois momentos, em 2009 (experiências do IEE) e mais atual (CA e EBST). Foram elencadas algumas situações mais pontuais, mas elucidadas como reveladoras e problematizadoras dos aspectos heurísticos postos em debate.

Temos especial interesse em compreender os significados partilhados, que do ponto de vista da cultura das mídias tendem a aparecer com um mínimo de coerência e inteligibilidade. Ainda que de forma múltipla, estes conferem subsídios para a constituição de referenciais que são compartilhados em larga escala, consolidando um sentimento comum, uma noção de pertencimento, porém de tipo além-fronteiras nacionais. A ideia de comunidade imaginada, de Benedict Anderson, retomada por Appadurai (1996), é muito inspiradora nesse sentido. Esse autor pensa a globalização sob a ótica das paisagens imaginárias (imaginary landscape): "essas paisagens são construçốes em bloco que eu gostaria de chamar de mundos imaginados, que são múltiplos mundos constituídos por imaginaçôes situadas historicamente e vivenciadas por pessoas e grupos espalhados por todo o globo" (APPADURAI, 1996, p. 33).

Do ponto de vista dos grandes centros comerciais e suas redes especializadas produtoras de mídias, as imagens aí promovidas apresentam influência incontestável, tendendo a serem arranjadas de forma que determinadas características sejam exageradas, delineando a imagem estereótipo (STAM; SHOHAT, 2006; GOFFMAN, 1988; RIAL, 2007). Esse processo resulta no ocultamento de outras formas de imagens, mais marginalizadas e ofuscadas pelos procedimentos de controle e de poder que definem uma determinada interdição discursiva (FOUCAULT, 2002). A forma como esses elementos são dispostos, nos mais diferentes meios materiais e imateriais, consolida-se como uma importante matriz dos significados e sentidos compartilhados. Tal disposiçâo serve para alimentar uma espécie de "arcabouço de possibilidades subjetivas", muito embora de fato decorra de algo objetivado por uma ordem regida pela dinâmica do consumo.

Nesse horizonte, permeado pela complexa dinâmica que habita os liames da cultura pós-moderna, o ponto a ser destacado está relacionado à forma com que as figuras femininas têm sido, ao longo do desenvolvimento das mídias, retratadas e 
inseridas em meio às narrativas, em consonância com as reivindicaçóes dos movimentos feministas que atravessaram a época. Em linhas gerais, podemos afirmar que os modelos e as configuraçóes identitárias adentram o contexto da expansão midiática onde se efetuam, em ritmo frenético, intensivos fluxos comunicacionais, altamente movimentados pela lógica do consumo. A tensão pela diversificação, provocada pela heterogeneidade e pela imprevisibilidade do público, conjugada com a necessidade de busca pelo nivelamento, oriundo da lógica da máxima audiência e consumo (MORIN, 1972a), fornecem um caráter bastante complexo ao processo de consolidação dos conteúdos midiáticos. A dinâmica cultural impóe de forma gritante seu caráter dialético através da atuação de diferentes forças: de um lado, a riqueza imagética possibilitada pelo uso das tecnologias da informação e, de outro lado, a necessidade de coerência e inteligibilidade em nome da eficácia da comunicaçáo. É nesse cenário de ambiguidades que a menina-super-poder-rosa "entra em ação". Como produto cultural, em cada meio e contexto ela será dotada de uma singularidade e incorporada de maneiras específicas, porém, interessa-nos compreender algumas determinantes de sua trajetória que serviram para fornecer-lhe alguns de seus principais contornos, vívidos nos contextos das apropriaçôes, entre identificaçôes e resistências infantis.

Martin-Barbero (2003) lembra a importância do contexto narrativo por onde essas imagens circulam. De olho no conjunto do processo, o autor procura interpretá-lo a luz de uma compreensão de gênero narrativo tomada como estratégia de comunicabilidade, onde fatos culturais e modelos dinâmicos, articulados com as dimensôes históricas do espaço de produção e apropriação, conseguem finalmente produzir sentido. Como resultado, temos que as imagens que ajudam a compor a menina, neste caso, são múltiplas e fragmentadas e somente adquirirão sentido quando rearticuladas no cotidiano através dos usos. De fato, imagens da super-poder-rosa encontram-se disponíveis para serem incorporadas, ressignificadas e rearranjadas a partir de um leque flexível de possibilidades, ainda que apresentem certos referenciais que lhe garantem um registro comum. Do lado dos produtores comerciais, levando em conta a intensa proliferaçáo com que as imagens são simuladas, um dos recursos retóricos das mídias, tais como a televisão e o cinema, consiste em buscar meios discursivos que simplifiquem a imagem-mensagem, tornando-a de fácil assimilação e conferindo-lhe, portanto, certa solidez, tal como a noção de estereótipo. Deve-se tal entorno, sobretudo, ao constante resgate de uma memória vivenciada no próprio contexto das narrativas midiáticas.

Em relação à pesquisa realizada com os grupos de crianças, considerados bastante representativos ${ }^{3}$ por conta de certa diversidade de tempos e contextos, ficou constatado que a mídia que exercia maior influência na composição de uma cultura 
midiática infantil era de fato os programas exibidos na televisão aberta e paga, com destaque às narrativas de desenho animado, informação coletada a partir de questionário enviado às famílias sobre práticas culturais e consumo midiático. Assim, partimos da premissa que a super-poder-rosa em sua estereotipia deve muito às representaçôes femininas presentes na tradição deste gênero narrativo, que, por sua vez, insere-se com mais vigor no contexto da produção televisiva ${ }^{4}$ viva ainda até os dias atuais, convivendo junto com outras modalidades tecnológicas como a internet e os jogos eletrônicos.

É evidente que há no interior da cultura das mídias um caminho bastante tortuoso, repleto de lacunas e incongruências, mas há a preponderância da jovem protagonista devido ao papel das primeiras personagens dos romances do século XIX e as da literatura infantil, com destaque às princesas dos contos de fadas. Alguns(mas) autores(as) apontam para uma tendência geral dessas personagens que consiste na adoçấo de uma postura predominantemente calcada na noção de passividade. Dedicaremos uma atenção especial a esse ponto devido à sua forte recorrência até o final do século XX, convivendo junto com outras formas de representação como a da superheroína e a da estudante de feitiçaria. Até esse momento, conforme defende Sherry Ortner (1996), a condição feminina desde a antiga literatura dos contos de fadas, costuma(va) aparecer caracterizada por uma espécie de não-fazer, dada à sua posição assumidamente passiva. Nessas histórias as mulheres eram/são retratadas em geral como vítimas: o sucesso de sua jornada, inclusive a passagem para o mundo adulto, implicaria necessariamente uma espécie de renúncia de agência. Tal comportamento pode ser verificado nas histórias clássicas amplamente conhecidas de princesas, como Rapunzel, Branca-de-Neve e A Bela Adormecida. Segundo a autora, as que comandam a ação, muitas vezes as vilãs, são punidas, porque elas devem esperar que "alguém faça algo por elas", mais precisamente um herói - masculino. Sua passividade é o que the garantirá o mérito de ser escolhida pelo herói, de modo que características como docilidade, delicadeza e fragilidade são as que a farão merecedora de um final feliz. $\mathrm{O}$ ápice de sua jornada culmina na efetivaçáo do casamento, justamente o desfecho da grande maioria das histórias de princesas:

No conto feminino mais comum, a heroína se casa no final. Mas, se tiver sido ativa no conto (e às vezes mesmo se náo tiver sido), tem invariavelmente de passar por várias provaçóes severas antes de merecer casar-se com o príncipe ou com qualquer homem. Essas provaçōes sempre envolvem símbolos e práticas de profunda passividade e/ou total inatividade, assim como práticas de humildade e subordinaçáo. (ORTNER, 1996, p. 60-61). 
Não muito diferentes são as agências das personagens dos gêneros narrativos tradicionalmente considerados femininos, com destaque ao melodrama, gênero consolidado desde os folhetins do século XIX e ainda bastante ressonante hoje em dia, sobretudo na forma das telenovelas latino-americanas. Muitos(as) estudiosos(as) (MORIN, 1975; RADWAY, 1984; ANG, 1996; PASSERINI, 1995) confirmam que tal gênero narrativo tem papel determinante para a consolidação de um universo feminino. Desse modo, em suas origens tal narrativa se destacou pela exaltaçáo de sentimentalismos, tendo como pano de fundo problemas familiares e de relacionamento, conflitos existenciais, frustraçóes e dilemas amorosos, isto é, na ênfase nos grandes dramas humanos ${ }^{5}$. No geral, são essas características que a diferem de outros gêneros narrativos, especialmente os de ação e aventura, associados ao público masculino (MIRA, 2003), de caráter pseudouniversal.

Do ponto de vista teórico como estratégia de análise, procuramos adotar uma postura crítica em consonância com os debates mais recentes voltados aos estudos de gênero, por um lado, e a problematização da categoria infância, de outro, ambos antenados à dimensão cultural e relacional que envolvem tais noçôes. Daí se extraem os significados que trilharão as matrizes de identidade infantil-feminina e vivificadas nas experiências infantis. Apesar dessas duas escolas de pensamento terem origem e motivaçóes distintas, elas encontram muitos pontos de convergência, já que chamam a atenção para o caráter político e cultural que são inscritos por meio das inter-relaçôes sociais, consagrando avanços e conquistas políticas como parte fundamental de suas análises.

As principais correntes que originaram os estudos de gênero vêm de um contexto encabeçado pelos movimentos feministas da década de 1970, momento igualmente importante para a redefinição dos papéis sociais num sentido mais amplo. Já os estudos que problematizam a noção de infância, a partir de sua dimensão histórico-social, também apontam a relevância e imanência dos jogos de poder que são evidenciados nas identidades e estilos de vida dos sujeitos, de onde se desdobra a condiçáo culturalmente desprivilegiada das crianças frente à sociedade e, em especial, sua íntima relaçáo com as mídias na contemporaneidade. De todo modo, a grande contribuição desses estudos esteve relacionada tanto à importância do contexto cultural a partir de suas dimensôes local e global quanto ao reconhecimento de que os significados inscritos são decorrentes das relaçôes sociais que demarcam as diferenças dicotômicas entre os sujeitos: masculinos/femininos e adultos/crianças.

Para fins de uma sistematização analítica, a seguir, problematizaremos, em separado, cada parte que dá nome, forma e inteligibilidade à menina-super-poder-rosa, como eixo norteador inclusive para apresentar algumas das vivências de campo com as 
crianças que se relacionam com tais temáticas. Começaremos pela menina, apontando as mudanças e continuidades na consolidação dessa imagem. Na sequência, faremos uso da noção super-poder, discutindo o incorporamento de um novo tipo de agência promovido por mudanças na própria figura feminina. Finalmente, será problematizado o rosa, como cor-símbolo definidora do universo infantil-feminino. Simultaneamente serão apresentadas situaçôes que endossam, dialogam, transgridem, confirmam ou contestem tal representação, ambígua mesmo em sua definição.

\section{A Menina}

De olho nas variáveis que definem as identidades, sobretudo as perpassadas pelas noçóes de gênero e de idade, num contexto dos intensos fluxos comunicacionais, partimos da premissa que ambas as construçôes discursivas não podem ser tomadas em seu sentido hermético, mas sim com ênfase em seu aspecto inter-relacional, histórico e contextual. Além disso, a trajetória de consolidação da imagem da criança se revela repleta de rupturas, lacunas e contradiçóes. Iniciaremos essa etapa analítica em direção a possíveis pistas que possam iluminar o debate sobre a consolidação da imagem da menina propriamente dita ${ }^{6}$.

Obviamente, a meninice feminina incide diretamente sobre a noção de criança. Do ponto de vista cultural, a infância é tomada enquanto constructo social (PINTO; SARMENTO, 1997), tendo as mídias hoje em dia um papel fundamental tanto para disseminação de sua visão hegemônica quanto para sua constante atualização aos moldes da cultura de consumo (BUCKINGHAM, 2000). Além disso, outras importantes instâncias sociais competem pela interpretação da infância no cenário atual, como o discurso pedagógico e o das instituiçóes de defesa da criança.

Buckingham (2000) argumenta que o termo infância seria definido por meio de dois tipos de discursos fortemente determinantes no intercruzamento com as mídias: aqueles para as crianças e aqueles sobre elas. Os discursos endereçados ao público infantil seriam aqueles produzidos pelos textos midiáticos e os sobre ele consistiriam nos diversos modos como as relaçôes das crianças com as mídias eletrônicas têm sido delineadas no contexto das pesquisas acadêmicas. Diante dessas pesquisas, o que o autor sinaliza sáo as concepçóes acerca da infância redefinidas pela presença da mídia nos contextos e cotidianos de todo o mundo. Ao mesmo tempo, pondera que, no cenário de um mundo globalizado, em que observamos uma distribuição absolutamente desigual da renda com impacto nos acessos e usos das mídias, como resultado se constata a coexistência de diferentes tipos de experiência de infância. No entanto, o ideal promovido pela sociedade de consumo altamente disseminado pelas mídias em escala 
global, acaba por oferecer um modelo que, embora não possa ser vivido da mesma maneira por todos/as, devido a restriçóes financeiras, por exemplo, ou outros tipos de interdiçóes culturais, acaba sendo, em larga medida, bastante conhecido e idealizado por todos $(a s)^{8}$. Isso se dá devido ao alcance das mensagens publicitárias que, muitas vezes, conseguem inserir-se e se mesclarem em meio aos costumes locais, nas suas mais diferentes formas de expressão.

A especialização do setor infantil no contexto comercial das mídias chegou ao ponto de desenvolver subdivisóes dentro da própria categoria. Dentre elas, a que mais se destaca está relacionada à divisão entre os meninos e as meninas. Com o propósito de reafirmação e valorização dessas identidades de gênero, constatamos uma forte e sólida oposição consolidada na diferenciaçáo entre os segmentos infantis masculino e feminino. Como consequência, temos que um dos primeiros mecanismos percebido pelas crianças que já nascem imersas nesse ambiente cultural tem a ver com a distinção do "o que é de menina" e "o que é de menino". Tal demarcação apareceu bastante evidenciada durante a experiência da pesquisa de campo com as crianças: além de compartilharem de referenciais, códigos, interesses e valores distintos, a separação entre meninos e meninas se efetuava também na segregação dos espaços de convívio e de sociabilidade, como que imaginariamente convivessem dois universos diametralmente opostos, separados, embora num mesmo espaço. Nos momentos das atividades livres, por exemplo, os meninos costumavam usufruir de espaços mais amplos através de atividades corporais repletas de movimentos, como corridas, jogos de bola, entre outras práticas que exigiam maior esforço físico, demarcando tais espaços para suas brincadeiras. Por outro lado, as meninas limitavam sua circulação a ambientes mais restritos, como bancos e cantos dos corredores do pátio escolar, como também nos relata Guacira L. Louro (1997), ao debruçar-se na análise das diferenças de gênero que incidiam sobre o comportamento das crianças nos contextos escolares.

Ainda que hajam transgressóes, foi observada nas práticas culturais infantis nos contextos escolares analisados a necessidade de uma intensiva negociaçáo relacionada ao rompimento dessas barreiras naturalizadas. $\mathrm{O}$ uso da quadra pelas meninas, a título de exemplo, dava-se a partir da aprovação e permissão dos meninos, tendo em vista que esse seria concebido como um território ocupado prioritariamente por eles. Houve uma situação de filmagem com as crianças de São Bonifácio (EBTS), em que cinco meninos brincavam de "tourinho", um jogo que era uma espécie de disputa de corpos no chão, ajoelhados, em que um empurrava o outro. Uma colega permaneceu observando de fora, insinuando querer participar da brincadeira, mas aguardando a permissão e o convite dos meninos, numa pressuposiçáo que esta prática não lhe era autorizada de forma imediata, carecendo dessa mediação masculina que não aconteceu. 
Nesta mesma linha, uma das atividades propostas para as crianças na etapa de pesquisa-intervenção na EBTS e no CA em 2014, consistiu na produção de desenhos de caneta colorida em papel sulfite, e foi unânime em todas as turmas - $83 \%$ das produçôes das meninas - nos desenhos das meninas aparecer de antemão a tradicional casa com janelinha e telhados com flores no jardim, mesmo que tenha sido solicitado que desenhassem, de forma mais livre possível, o que mais gostassem e se identificassem. Nessas representaçôes há um forte indicativo da centralidade que a metáfora da casa e suas simbologias ocupa nos imaginários infantis femininos. No contexto dos jogos sérios (ORTNER, 1996), percebemos uma tendência à preocupação maior das meninas em relação à aceitação e à correspondência da expectativa da pesquisadora, adulta, revelando uma possível inclinação à subserviência, aparentemente tão investida nessas práticas. Por sua vez, na produção dos meninos, além de haver o uso de cores mais neutras e escuras, no contexto das duas escolas, a grande maioria desenhou objetos e equipamentos que incitam movimentos e força como serras elétrica, motos, carros, helicópteros, barcos e heróis de desenho animado, confirmando a ideia de que a cultura infantil masculina remete ao mundo da ação, do movimento e da técnica.

Esse aspecto último coincide com as açóes dos personagens masculinos e femininos dos programas infantis. No tocante ao desenho animado, gênero narrativo mais assistido por esse público, a maior parte dos exibidos na televisão, durante muito tempo se dirigiu para "as crianças em geral", dentro do projeto da cultura de massa, que tinha o homem médio como seu denominador comum (MORIN, 1972a). No limite, predominaram os personagens masculinos, principalmente de dois tipos: os superheróis, na linha dos personagens de quadrinhos como Super-Homem, Homem Aranha e Batman; e, de outro lado, os cômicos, como Pica Pau, Pato Donald ou Pernalonga. Conforme levantamento feito por Mareuse (2002), percebemos a quase inexistência de personagens femininas como protagonistas até finais dos anos de $1990^{\circ}$ - com exceção das princesas dos contos de fadas, investidas de uma postura mais passiva, como já mencionado.

Em linhas gerais, as protagonistas começaram a despontar nos desenhos animados a partir dos anos de 1980, como consequência da expansão e especialização dos mercados e como aposta no potencial setor infantil. Dentre os desenhos para meninas, somavam os personagens de animais "fofinhos", dóceis e infantilizados, que costumam(vam) exaltar sentimentos considerados "essencialmente" femininos, como cuidado, carinho e proteção, por exemplo, Pequeno Pônei, O Mundo de Moranguinho, Ursinhos Carinhosos, entre outros. Kline (1995) reflete a respeito dessa tendência que então tomava forma, no qual música, fantasia e mundos mágicos consolidavam um cenário particular, um mundo "encantado" e amplamente impulsionado pelos interesses comerciais: 
Os marqueteiros viram a necessidade de um tipo de animação estilizada que pudesse promover também as fantasias e valores lúdicos das meninas pequenas [...] para definir uma estilística de animação distintamente feminina, suas sensaçóes, aparência, voz e cor foram elaborados tendo em mente um nicho de mercado mais especializado ${ }^{10}$. (KLINE, 1995, p. 306).

Em geral, na cultura infantil, além dos elementos específicos que demarcam esse grupo social, há também uma apropriação ou compartilhamento de certos referenciais adultos. No contexto do consumo, destacam-se aqueles ligados às atividades lúdicas e de lazer, que podem ser tomadas como um importante elo entre os grupos adulto e infantil (MONNOT, 2009). De modo que, tanto as meninas, as jovens e as mulheres quanto os meninos, os jovens e os homens, do ponto de vista da cultura do consumo, compartilham de utensílios, vestimentas e hábitos reconhecidos como típicos de cada gênero, ainda que culturalmente com diferenças em nuances de acordo com a geração no qual o fator da fantasia parece ganhar em profundidade quanto menor for a idade.

Nessa direçáo, o que observamos é que para os meninos vigora o universo dos esportes como futebol, vôlei e corridas, além de bens de consumo símbolo de status no mundo adulto masculino como automóveis, tênis, relógios e meios eletrônicos. Como distintivos mais ligados ao infantil para esse gênero, surgem os temas dos heróis de desenhos animados, que perfilam uma fantasia mais exacerbada, podendo ser traduzida como uma espécie de idealização vinculada aos atributos de poder e força. Para as meninas sobressaem os produtos que exaltam a beleza, como maquiagens e outros acessórios, como bolsinhas e saltos, bem como as bonecas: tanto para suas brincadeiras em que simulam um papel maternal quanto para suas projeçôes nas quais imaginariamente se incorporam em bonecas, como Barbie e Polly. Dentre os temas de suas brincadeiras vigoram os passeios nos shoppings, as idas ao saláo de beleza, os cenários de grandes e luxuosas residências. Em relação aos desenhos animados especializados neste setor, somam-se personagens dóceis, encantados e infantilizados, como My Litlle Poney, Moraguinho, Pucca e Hello Kitty, além de fadas e princesas de contos de fadas, estas promovidas em larga medida pelas adaptaçôes e releituras dos filmes da Disney ${ }^{11}$.

$\mathrm{Na}$ observação das brincadeiras e jogos infantis, uma prática em especial chamou a atenção através da forma como meninos e meninas colecionavam, trocavam e jogavam com suas "cartinhas". Tratavam-se de figuras adesivas colecionáveis, vendidas em bancas de revista que as crianças, em seus tempos livres, podiam efetuar trocas e competiçóes. No CA, na hora do recreio percebemos a presença dessa prática presente 
em praticamente todas as turmas de crianças das séries iniciais. Nas cartinhas das meninas, menos frequentes que a prática dos meninos, notamos as figuras de desenho animado do filme da Frozen e das Monster High, já para eles estava em alta as cartas dos personagens do Pokémon. Mas o que chamou a atenção foi justamente uma diferenciação entre os modos de jogá-las e trocá-las entre os grupos de meninos e meninas. Enquanto os meninos realizavam disputas com suas cartas ao estilo do tradicional do jogo supertrunfo, em que poderes e características dos personagens das cartas eram colocados em disputa, vencendo o mais forte (valendo a cartinha do adversário), no caso das meninas a regra básica do jogo estava voltada à troca, com vistas ao preenchimento do álbum de figurinhas, exclusivamente. Nessas práticas notamos mais uma vez o dinamismo das trocas dos meninos, sendo mais frequentes em situaçóes e lugares mais improváveis e flexíveis como filas, parques, quadra, e já para as meninas percebemos a necessidade de preparar o ambiente, a fim de possibilitar a conferência com maior atenção das cartas inéditas ou repetidas, estando elas munidas do álbum ou acompanhadas de listas com a numeração das cartas faltantes. Mais uma vez, chamou a atenção, além das temáticas, a prática da coleção, da organização, da precisão e do cuidado no caso das meninas e, por sua vez, a competição, o dinamismo e a ação nos jogos de cartinhas dos meninos.

$\mathrm{Na}$ escolha e nos dias dos brinquedos, saltou aos olhos na última pesquisa no CA e EBTS a preferência das meninas por bonecas, entre os bebês ou a jovem esbelta, na figura da princesa e nas variaçóes de estilo da boneca Barbie (de roqueira e superheroína a noivas e princesas). Em linhas gerais, na representação das personagens femininas e em suas práticas e brincadeiras mesclam-se, sob a denominação da menina, tanto aspectos ligados à meninice, tal qual a ingenuidade e a graciosidade simbolizadas nas figuras "fofinhas" de personagens animados, quanto se incentivam certas características femininas que também vigoram no mundo adulto como a valorização da boa forma do corpo jovem, atraente e sedutor. Este último ponto acaba sendo incorporado pela cultura infantil feminina não apenas de forma projetiva, mas reapropriada sob uma nova roupagem, incorporando elementos que tentam preservar uma pseudoinfantilidade. No entanto, mesmo com a presença de personagens femininas mais ousadas, destacamos o fato de as práticas continuarem reafirmando em primazia a dimensão do cuidado, enquanto os meninos têm exaltado a dimensão da ação e da competição.

\section{A Superpoderosa}

A imagem da superpoderosa vem de um processo de reconfiguração do feminino, onde se destaca uma série de transformaçôes dos papéis ${ }^{12}$ de gênero, 
culminando num movimento de autoafirmação feminina. Vale destacar de antemão que a consolidaçáo da "poderosa" não anulou nem substituiu outras formas de representaçôes femininas anteriormente existentes. De fato, a afirmativa do poder conquistado pelas mulheres inseriu-se ao lado de outros aspectos tradicionais ligados à "feminilidade", coexistindo com eles, ainda que tencionando e reformulando-os.

Almeida (2003), num estudo voltado à recepção de telenovelas, constatou como a publicidade no interior dessas narrativas tem procurado trabalhar com os sonhos captados em determinados momentos históricos. Aqui a autora exalta a imagem da supermulher, que "dá conta de tudo e é bonita", constituindo de fato a grande aspiração de toda mulher, o que tem sido percebido nos diferentes discursos, tanto das produtoras quanto das espectadoras interlocutoras. Assim, a supermulher vislumbra um caminho de realização presente nas narrativas midiáticas, que tem a ver com: ser jovem, bonita, inteligente, bem-sucedida profissionalmente, ter uma boa casa, filhos/as e um marido. $\mathrm{O}$ adjetivo da beleza adquire uma importância central, sendo bastante reforçado pelos discursos publicitários: "À medida que a sociedade se moderniza e as mulheres assumem novos papéis, o ideal da beleza feminina torna-se uma imposição à obtenção de sucesso na vida amorosa e mesmo profissional" (GHILARDI-LUCENA, 2003, p. 168).

Indo mais longe no tempo, nas tradicionais histórias de princesa percebemos a centralidade que a beleza adquire como um dos principais atributos e garantia de sua maior realização: a conquista do príncipe encantado. A respeito dos contos de fadas, Corso e Corso (2006, p. 76) confirmam tal prerrogativa: "Os atrativos femininos seriam uma arma privilegiada de conquista de posição para uma mulher”. Entendido como poder de sedução, este se diferencia radicalmente dos outros tipos por se dar por meio da conquista, uma postura mais branda e negociada, náo impositiva, coercitiva e invasiva como as outras formas de poder que fazem uso da violência. Assim, como prática que envolve elementos mais subjetivos, que exigem um certo domínio de práticas de conquista, tais como charme, elegância e beleza, inscritas num conjunto performático, as sedutoras fazem uso de inúmeras técnicas, de acordo com o fim desejado. Além disso, nos jogos de sedução o poder é consentido, nas sutilezas das práticas cotidianas.

Quanto ao desempenho dos heróis e das heroínas, do ponto de vista das crianças, um episódio observado durante a pesquisa realizada com a turma do IEE mostrou-se bem apropriado para ilustrar a percepção e incorporação das crianças acerca da atuação desses personagens. Dentre os diferentes tipos de recursos utilizados na realização da pesquisa com as crianças, um deles esteve relacionado à gravação de vídeo de suas brincadeiras. Dispostos de uma pequena filmadora de mão, a proposta era que 
fossem formados trios entre as crianças para produção de uma pequena história de herói(s) ou heroína(s).

Como já era presumido, as crianças organizaram-se formando alianças com crianças do mesmo gênero. De uma maneira geral, os meninos representaram os superheróis, enquanto as meninas mostraram uma tendência a corporificarem mais as princesas de contos de fadas, também bastante famosas nas mídias e na cultura dos contos de fadas. Nas atividades dos meninos, prevaleceu um enredo repleto de performances de luta, com direito a simulação de efeitos especiais e sonoros, combate a monstros e inimigos, onde eles não hesitavam em representar vilóes ou inimigos, pois a ação performática dos golpes se configurava como aspecto central na trama.

No caso das meninas, notamos na maior parte das representaçóes uma preocupaçáa maior quanto ao desencadeamento do enredo da história, sobretudo relacionado à distribuição dos papéis: uma apenas haveria de ser a princesa e inevitavelmente as outras teriam que ser coadjuvantes, no papel de mãe, irmã ou amiga. Aqui, notamos a recorrência quase que unânime de uma negociação inerente à distribuição das personagens, revelando uma tensão: a iminência de uma situação de conflito por conta da eleiçáo de quem haveria de "ser" a princesa, a personagem principal. Em suas histórias de princesa, a presença do príncipe consistia num aspecto central, no entanto, não observamos nenhuma das meninas envolvidas se candidatando a representá-lo. Igualmente não notamos a participação nem mesmo de personagens com feiçôes anti-heroicas ou de vilâs, de modo que aquelas que não representaram a princesa tenderam a corporificar a mãe ou a irmã. O desfecho num dos casos que gostaríamos de destacar com uma dupla de meninas, em específico, foi o encontro com o príncipe "imaginário" onde vigora a máxima: "e viveram felizes para sempre! Fim". Tanto para eles quanto para elas, não observamos nenhuma situaçáo em que a criança se passaria por um personagem do sexo oposto. Essa atividade, aqui descrita de maneira sumária, ilustra a diferença entre as semânticas narrativas de meninos e de meninas. Aqui, evidenciam-se alguns dos códigos distintos que regem os mundos infantis masculinos e femininos, bastante estimulados pela mídia, embora ambos sejam marcados culturalmente pela forte presença do fator lúdico, imaginativo e inventivo, pelo qual as crianças recriam elementos.

Em finais dos anos de 1990, constatamos o surgimento de um desenho animado norte-americano, cujas protagonistas eram três meninas super-heroínas: as MeninasSuper-Poderosas (1998). Seu sucesso foi rapidamente estendido para o mundo todo e seu furor repercutiu não apenas no segmento infantil, mas, sobretudo, com mulheres independentes e bem-sucedidas profissionalmente que rapidamente se identificaram com as personagens, as quais eram exibidas estampadas em seus objetos pessoais, 
roupas, buttons e aparelhos eletrônicos. Por conta de seu caráter inovador tanto na estética como na proposta narrativa, tal fenômeno também foi bem aceito por grupos que reivindicavam reconhecimento e valorização da diversidade cultural, sobretudo relacionada à orientação sexual, como grupos de Lésbicas, Gays, Bissexuais, Travestis, Transexuais e Transgêneros (LGBTT). Aliás, esse fenômeno se tornou marca de uma nova onda identitária e libertária que se consolidou, principalmente, entre as mulheres dos universos urbanos.

Notamos com o surgimento dessa animação, uma tendência, ainda que tímida se comparada à representatividade dos heróis masculinos, de personagens femininas protagonizarem as séries, sem seguirem estritamente as marcas definidoras das protagonistas até entâo existentes, as princesas. A grande inovação consistiu no fato dessas personagens mais atuais incorporarem os atributos antes restritos aos heróis exclusivamente, como a força, a coragem, a habilidade e a destreza, ainda que conjugadas com as tradicionais características femininas como docilidade, carisma, meiguice, beleza e sentimentalismos, cujo ineditismo consistiu em figurarem no contexto das produçôes infantis de alcance global. No entanto, ainda assim elas insinuam mais uma cópia malfeita dos similares masculinos, os que seriam de fato os legítimos protótipos do macho militar guerreiro, como os super-heróis dos quadrinhos e dos desenhos animados (STEINBERG; KINCHELOE, 2004). Isto é, apesar das representantes femininas em geral serem fortes e lutarem, sejam como espiãs da série $A s$ Panteras da década de 1970 ou como super-heroína no corpo da ilustre MulherMaravilha ou das personagens infantis aqui destacadas, elas não soam ser táo fortes à altura dos personagens masculinos.

Se olharmos atentamente no interior das narrativas de super-heroínas veremos que igualmente importante tanto quanto combater os inimigos no caso das superheroínas, estão às temáticas voltadas à construção cultural narrativa reconhecidamente feminina, que contempla ao mesmo tempo: (1) as preocupaçóes relacionadas aos interesses públicos da sociedade, aos moldes dos valores ligados à modernidade (manutenção da ordem social, a defesa da figura do Estado, o nacionalismo, os princípios cristãos, o ideal da família burguesa etc.), centrais nas narrativas dos heróis de herança norte-americana; (2) as motivaçôes e os anseios voltados à constituição da família traduzida na preocupaçáo constante na busca de um possível parceiro do gênero oposto; e, consequentemente, (3) a centralidade da boa aparência e a importância de seu desempenho no sentido de "agradar" um possível pretendente. No próximo item, exploraremos um pouco mais esse contraditório universo com o foco nos elementos que conferem forma, conteúdo e corà sua imagem. 


\section{A cor-de-rosa}

Apesar da riqueza e da complexidade dos referenciais que servem para compor uma espécie de ideal feminino contemporâneo, modelo bastante explorado pela cultura das mídias, há um componente presente neste universo que merece uma atenção especial: a predominância da cor rosa. Aliás, esse tom definitivamente sinaliza, demarca e representa as simbologias do universo onde vigoram as novas feminilidades.

Koller (2008) concebe essa cor como definidora de gênero e sexualidade femininos nas linguagens visuais, chamando a atenção para os significados suscitados, especialmente nos meios publicitários. A autora realiza uma análise semântica, chamada de semiótica social, com a qual faz um levantamento acerca da percepçáo do rosa entre diferentes sujeitos ingleses. Em sua análise confirmou e reiterou a associação às simbologias da feminilidade, porém percebeu variaçôes de seu uso dentro de contextos diferenciados. Pôde concluir também que há nuances de significados que variam de acordo com a tonalidade do rosa: num tom mais claro ele insinua sentimentos como romance, infância, sonho, charme, delicadeza e amor, por outro lado, num tom mais vibrante, conhecido como pink, seus/suas informantes o associaram à luxúria, ousadia, sedução, paixão e excitação, enfim, ideias que remetem mais a uma perspectiva de transgressão e agência.

No contexto brasileiro, percebemos o uso de diferentes tons de rosa na cultura midiática infantil feminina, foco de interesse neste momento. Durante a pesquisa empírica junto às meninas verificamos sua presença como via de regra em, praticamente, todos seus artefatos e objetos de uso pessoal: desde adornos como anéis, pulseiras, batons, bolsinhas, minissaias, sandalinhas e chiquinhas de cabelos, pulseirinhas, signos de feminilidade por si só, até tênis, materiais escolares e carrinhos de brinquedo, assim relegados ao universo exclusivo feminino pela simples presença dessa cor. Quanto aos meninos, eles pareceram sentir um misto de admiração e repúdio frente a tudo que recebe essa tonalidade: o primeiro aspecto se manifesta de forma mais velada, como respeito relacionado ao encanto e ao charme inscritos no universo feminino. O sentimento de repúdio está ligado à rivalidade promovida por uma cultura sexista disseminada na escola e reforçada pelas mídias (LOURO, 1997). Além disso, o uso do rosa pelos meninos se torna assim impensável, pois remete ao mundo da passividade, o da feminilidade ${ }^{13}$.

Entretanto, as diferenças na percepção das nuances da tonalidade rosa presente nas falas das meninas nos revelou que quanto mais intensa e vibrante a cor, na direção do pink, proporcionalmente aumentava o sentimento de orgulho quanto à feminilidade, pela via de sua autoafirmação. Um episódio vivenciado no IEE, que ilustra bem essa 
constatação, refere-se a uma atividade de gravação em vídeo, especialmente de uma menina do grupo acompanhado no Instituto, que narra uma história em quadrinhos de sua autoria: a protagonista era uma princesa, num mundo todo cor-de-rosa, tudo seu era rosa. Como ela era a personagem principal - e, consequentemente, a que reunia a maior quantidade de qualidades dignas de uma protagonista - era, segundo seus dizeres, "bem rosa" (pink).

Inclusive as personagens de desenhos animados apontadas pelas crianças entre suas preferências, tanto exibidas em seus adereços e brinquedos quanto presentes em seus repertórios, apresentam em sua grande maioria a presença dessa cor em seus corpos e vestimentas. A variaçáo da tonalidade do rosa explicita e reitera a distinção de significados apontada por Koller (2008): o rosa claro atribuído às princesas e o rosa mais vibrante às personagens mais ousadas, estas últimas associadas, sobretudo, à última tendência inaugurada mais recentemente na imagem das bonecas (com versão em série animada) estudantes de escola de feitiçaria, como as Monsters High.

Uma situação bastante reveladora das distinçôes de gênero, ocorrida na brinquedoteca do CA, aconteceu numa roda de cerca de sete crianças, entre meninos e meninas, onde a brincadeira era a de confeccionar pulseirinhas de elásticos coloridos. Durante o processo surgiu a ideia de iniciarem uma brincadeira de "lojinha" de faz de conta, onde seus produtos seriam "vendidos". A partir de então, começaram as negociaçôes sobre preços e organização das vendas. Após uma rápida conversa, meninos e meninas decidiram que haveria distinçáo entre os preços das pulseiras e, assim, um deles confeccionou um cartaz com os seguintes dizeres: "pulseira de menino 10 reais e pulseira de menina 5 reais”. Questionados(as) sobre as diferenças nos preços, um menino que confeccionava uma pulseira, fez primeiramente que náo entendeu a pergunta e ao ser indagado novamente respondeu: "porque tem pulseira de menino e pulseira de menina, ué", permanecendo com ar de indiferença e mostrando-se mais atento a sua tarefa de ordenar as cores da pulseira que estava sendo confeccionada por ele, como se de fato a pesquisadora estivesse "atrapalhando". Uma menina ao lado, ouvindo a conversa, percebendo a indiferença, quis então mostrar-me o que realmente diferenciava as pulseiras. Revelou-me no caso que eram justamente as cores atribuídas a cada gênero, percebidas unanimemente, então, como normas naturalizadas: cores claras e vibrantes atribuídas às meninas, com destaque ao uso do rosa, e cores escuras e mais "sérias" relegadas ao masculino. Nesta experiência ficou evidenciado o modo como as atribuiçôes das cores por gênero, além de aparecerem como algo essencializado, binarizado e impositivo, também revelam a desvalorização e banalização do universo feminino, de modo que o questionamento sobre tal diferenciação soou como algo muito inusitado e incompreensível pelas crianças, tendo em vista a aparente e óbvia pseudolegitimidade desta condição. 
Assim, a vivacidade da cor comporta certo orgulho e representa a marca definidora das feminilidades infantis que busca, de um lado, reforçar e reafirmar sua identidade, de modo a se diferenciar positivamente. Por outro lado, há ainda uma tendência à desvalorização e inferiorização de tudo que é remetido à esfera do gênero feminino, apontado pelo grupo dos meninos como algo desinteressante, exterior, desvio e alheio.

\section{Considerações finais: reconstruindo a menina-super-poder-} rosa

No contexto de uma sociedade marcada pelo consumo, tão importante quanto os elementos que ajudam a compor a imagem da menina-super-poder-rosa, destacam-se os usos e leituras que são dela feitos, sobretudo a potencialidade criativa propiciada pela forma como seus elementos são rearranjados. Apesar de sua condição multifacetada, compreendemos que há um leque matricial de referenciais, cujo sentido é histórico e cultural. Tomado em seu conjunto, fornece as predisposiçóes de um estilo de vida infantil-feminino bastante presente no imaginário das crianças do mundo todo, mas apropriado e ressignificado de modo distinto dependendo do contexto.

De todo modo, náo há como negar que o contexto em que estes referenciais são promovidos encontra-se marcado pela máquina do consumo, pela lógica da máxima lucratividade. Se não houver nenhum tipo de questionamento, resistência ou movimento de intervenção crítica $^{14}$, a tendência, portanto, é cada vez mais que tais referenciais fiquem colados aos valores de uma sociedade centrada no poder, na lógica de consumo, de um lado, e na hierarquizaçáo dos gêneros e no sexismo, por outro. Consequentemente, como é o caso da super-poder-rosa, as posturas e os valores que se inscrevem na cultura do rosa remetem à supervalorização da aparência física em detrimento da inteligência, como a exaltação dos hábitos consumistas, como ir ao shopping, e na desvalorização do universo feminino exaltado pelo aspecto da futilidade.

Tradicionalmente, as crianças, tomadas como um "vir-a-ser", vêm sendo educadas para se tornarem homens ou mulheres, dentro da normatização dos gêneros, de modo que, enquanto os meninos foram encorajados desde muito pequenos à competividade, à agressividade e a encarar as situaçóes sob a ótica da objetividade, as meninas, em geral, têm sido ensinadas a serem contidas, a focarem seus interesses nas atividades domésticas e a serem mais emotivas e sensíveis.

Num mundo marcado pelo poder do consumo, a infância muda sobremaneira sua forma de inserçáo no meio social e a menina, como um dos últimos redutos da 
antiga ideia de sacralidade infantil, adquire nesse contexto novos contornos, através dos quais sua aparência de inocência é refundamentada devido, em grande medida, ao papel do poder de escolha propiciado pelo mundo do consumo (BAUMAN, 2007). Um grande exemplo dessa variação encontramos na figura da personagem Elza, do filme Frozen: uma aventura congelante (uma produçáo da Walt Disney-Pixar, de 2013), cuja trama gira em torno do amor entre duas irmás, sendo esta personagem principal inovadora em sua atitude e postura libertária: orgulha-se em ser sozinha e feliz em seu castelo de gelo, ou seja, sem a figura do marido e dos filhos. Vale destacar que talvez por conta também da alta e complexa estética visual e sonora dessa grande produção, presenciamos situaçóes lúdicas de encenação do enredo desse filme em nossa última pesquisa em ambos os contextos escolares. Inclusive realizamos um registro audiovisual, em plano-sequência, de uma encenação da narrativa deste filme, em que participaram quase que a totalidade de meninos e meninas de uma das turmas, durante cerca de quinze minutos ininterruptos no espaço da brinquedoteca do CA, de forma espontânea, mas altamente orquestrada. Já em São Bonifácio, a música do filme cantada pela personagem Elza ("Livre estou") figurou como marca identitária das meninas em grande parte de suas produçôes fílmicas, realizadas na etapa de intervenção com o propósito de registro de suas vivências escolares. Pois bem, em meio a todos esses movimentos, o que podemos aferir sobre a imagem da menina?

Eis a menina-mônada: uma imagem que, tal como um discurso (BARTHES, 1972), inscreve-se nos corpos generificados, fiéis a uma ditadura das imagens femininas, em oposição às imagens masculinas, ambas autoexcludentes. Elas estão presas a uma inteligibilidade, vítimas de uma coerência em meio a um caos de imagens, discursos e outros fragmentos. Menina-mullher, mulher-menina, às vezes só menina, às vezes só mulher. A super-poder-rosa habita um pouquinho cada uma delas. É mais fácil defini-la pelo que ela não é: Ela não é masculina. Ela não é feia. Ela não é velha. Mas fundamentalmente é necessário a presença da graciosidade.

$\mathrm{O}$ rosa define em sua simbologia a mistura de tudo aquilo que se atribui às feminilidades: a criança, o bebê, tudo aquilo que tem graça, carisma e, acima de tudo, seduz. Aqui, apareceram alguns fragmentos dessa imagem em situaçóes concretas e reflexóes. Talvez existam muitas outras combinaçóes, imagens e tipos facilmente identificáveis e conhecidos. Isso acontece porque sua existência deve, principalmente, ao tecido cultural. Elas, as meninas, têm poder. Às vezes "mandam com jeitinho", conforme definiram táo bem as meninas da pesquisa, outras vezes, ninguém nem percebe que exerceram agência. No entanto, podem ser também fortes e poderosas. A agência da super-poder-rosa é leve, mas viva, criativa e envolvente. É alegre, infantil, lúdica e dialética. É moça, mulher e menina. É insinuante sem ser provocante, é santa 
sem ser sacra, é ousada sem ser vulgar. É também estereotipada, impositiva e restritiva. Inferiorizada, representada e aprisionada em sua política de representação. Porém, comporta o desvio, a resistência e a transgressão. E, finalmente, é múltipla, porque é, ao mesmo tempo, aprisionadora e libertária.

\section{Notas}

${ }^{1}$ Este último aspecto refere-se às pesquisas realizadas mais recentemente, no estágio pósdoutoral. Um aspecto importante é que os colégios envolvidos neste período, Colégio Aplicação e Escola Básica de São Tarcísio, configuraram-se como escolas piloto para a implantação do Programa Um computador por aluno (UCA), do governo federal. Também se configuram como escolas parceiras do projeto do programa de pósgraduação ao qual a pesquisa se vincula. A pesquisa anterior envolveu o Instituto Estadual Catarinense, cuja escolha se deu pela sua suposta representatividade quanto à variedade de público e pelo fato de estar localizado na região central de Florianópolis.

${ }^{2}$ Livre tradução da autora do original: "Imagined worlds, that is, the multiple worlds that are constituted by the historically situated imaginations of persons and groups spread around the globe" (APPADURAI, 1996, p. 33).

${ }^{3}$ Apesar das pesquisas terem sido realizadas em momentos distintos, há semelhanças nas preferências das crianças por determinados apelos midiáticos endereçados às meninas. A maior diferença se relaciona ao fato de o segundo momento apresentar como inovação a emergência das personagens "monstrinhas", uma tendência inaugurada pela indústria de brinquedos casada a de desenho animado, cujas bonecas são estudantes de uma escola de feitiçaria - Monster High e Ever After High. Estas foram vistas como um fenômeno importante e recente, mas não constituirão o foco deste artigo pelo simples fato de sua presença aparecer de modo ainda mais tímido nas práticas culturais infantis.

${ }^{4}$ Sobre a lógica que rege o fluxo narrativo televisivo, Martín-Barbero e Rey (2001) destacam a sedução de imagens e sons, os padróes de envolvimento e apelos emocionais, a ficcionalizaçáo do real, a simplificação da linguagem e a estereotipaçáo das personagens.

${ }^{5}$ Apesar de o público feminino adulto constituir-se como o modelo de espectador/a em que se baseiam os produtores, a partir do momento em que os romances "migram" para os meios audiovisuais começa a delinear-se uma linguagem voltada para a família, em que há o incorporamento de outros gêneros narrativos, como açáo e aventura, em vista a um tipo de público fundamentado na ideia do homem médio, que, segundo Morin (1972a, p. 46), consiste num modelo ideal, abstrato, sincrético e múltiplo, e incorpora as características tidas como "universais", consolidando-se em "um homem-criança [...] que é curioso, gosta de jogo, de divertimento, do mito do conto".

${ }^{6}$ Tal compreensão se revela salutar, de modo que os demais aspectos constituem desdobramentos desta, por isso, dedicaremos maior atenção. 
${ }^{7}$ Maria Luiza Belloni (2009), em seu livro sobre Sociologia da Infância, reconhece que as transformaçóes relativas à infância estão entre as mais significativas mudanças socioculturais ocorridas no final do século XX, sendo a criança, a partir de entáo, conhecida como um valor em si. Nesse sentido, enfatiza o papel desempenhado pelas mídias no processo de socialização das novas gerações.

${ }^{8}$ Buckingham (2000) afirma que muitos críticos apontam que a associação dos desenhos com a comercialização de produtos não constitui mais uma atividade secundária, mas, sim, primária: os fabricantes não apenas compram as licenças, mas se envolvem durante toda sua produção, participando das decisões centrais sobre forma e conteúdo, sempre voltados ao sucesso de vendas. Segundo o autor, os produtores rotulam os desenhos animados como "anúncios com tamanho de programas". Não é à toa que verificamos que a lista dos produtos mais vendidos tem se revelado dominada por produtos ligados à TV, sendo conhecidos por grande parte das crianças de diversas partes do mundo.

${ }^{9}$ Ainda nos dias atuais, as poucas existentes costumam ser consideradas exclusivamente remetidas à vertente feminina, ou seja, especializados em atender à "especificidade" do público infantil-feminino.

${ }^{10}$ Tradução da autora do original: "Marketers saw the need for a kind of animation stylistic that could promote girl's toy lines too and reflect little girl's fantasies and play values. [...] to define a distinctively feminine animation stylistic its feel, looks, voice and colour were crafted with a narrower market niche in mind" (KLINE, 1995, p. 306).

${ }^{11}$ Carolina Fossatti (2009) realiza um levantamento acerca da evolução na representação das princesas da Disney, começando por Branca de Neve de 1927 até chegar à atualidade com as protagonistas de etnia e comportamentos mais variados e complexificados, como Anastácia e Mulan. No entanto, ressalta o caráter submisso, subserviente e dócil presente no status de todas elas.

12 "Papéis seriam, basicamente, padróes ou regras arbitrárias que uma sociedade estabelece para seus membros e que definem seus comportamentos, suas roupas, seus modos de se relacionar ou de se comportar [...]. Através do aprendizado de papéis, cada uma deveria conhecer o que é considerado adequado (ou inadequado) para um homem ou para uma mulher numa determinada sociedade e responder a essas expectativas". (LOURO, 1997, p. 24).

${ }^{13}$ "O que observamos no universo masculino foi uma exigência velada para que o menino se afirme constantemente em direçáo a tornar-se 'homem de verdade' e para isso consolida-se como necessário um intensivo esforço performático [...]. Não obstante, para que existam esses homens é porque presume-se o contraponto do 'homem fracassado', cuja conotação é bastante negativa: aquele que não consegue atingir sua "masculinidade plena" é tido como fraco, gay, passivo etc. Nesta direção, a afirmação da virilidade deve ser constantemente afirmada para não correr o risco de 'regressar' à feminilidade, já aparentemente dada" (ODININO, 2009, p. 266).

${ }^{14}$ Um exemplo de movimento crítico a reificação da cultura das meninas está na campanha "Rosa é uma droga", promovida num blog por duas mães inglesas. Ver: <http://www.pinkstinks.co.uk/>. Acesso em: dez. 2009. 


\section{REFERÊNCIAS}

ALMEIDA, Heloísa Buarque. Telenovela, consumo e gênero: muitas coisas mais. Bauru, SP: Edusc, 2003.

ANG, Ien. Living room wars: rethiking media audiences for a postmodern world. New York: Routledge, 1996.

APPADURAI, Arjun. Modernity at large cultural dimensions of globalizotion. London: University of Mimmesota Press, 1996.

BARTHES, Roland. Mitologias. São Paulo: Difusão Europeia do Livro, 1972.

BAUMAN, Zigmunt. Vida Líquida. Tradução de Carlos Medeiros. Rio de Janeiro: Zahar, 2007.

BELLONI, Maria Luiza. O que é sociologia da infância. Campinas, SP: Autores Associados, 2009.

BUCKINGHAM, David. After the death of childhood: Growing up in the age of electronic media. Londres: Polity Press, 2000.

CORSO, Mário; CORSO, Diana. Fadas no divã: psicanálise nas histórias infantis. Porto Alegre, RS: Artmed, 2006.

FOSSATTI, Carolina. Cinema de animação e as princesas: uma análise das categorias de gênero. In: CONGRESSO DE CIÊNCIAS DA COMUNICAÇÃO NA REGIÁO SUL, 10., 2009, Blumenau. Anais... Blumenau, SC: Intercom, maio 2009. Disponível em:

<http://www.intercom.org.br/papers/regionais/sul2009/resumos/R16-0120-1.pdf>. Acesso em: nov. de 2014.

FOUCAULT, Michel. A Ordem do Discurso. São Paulo: Loyola, 2002.

GHILARDI-LUCENA, Maria Inês. Representaçôes do Feminino. Campinas, SP: Átomo, 2003.

GOFFMAN, Erving. La ritualisation de la féminité. In: WINKIN, Yves. Les Moments et Leurs Hommes. Paris: Seuil/Minuit, 1988.

KLINE, Stephen. Out of garden: toys and children's culture in the age of TV marketing. London: Verso, 1995. 
KOLLER, Veronika. Not is just a color: pink as a gender and sexuality marker in visual communication. Visual Communication, London, v. 7, n. 4, p. 395-423, nov. 2008. Disponível em: < http://vcj.sagepub.com/content/7/4/395.abstract>. Acesso em: nov. de 2014 .

LOURO, Guacira. Gênero, Sexualidade e Educação. Rio de Janeiro: Vozes, 1997.

MAREUSE, Marcia. 50 anos de desenho animado na Televisão Brasileira. 2002.

Dissertaçáo (Mestrado em Ciências da Comunicação) - Universidade de São Paulo, São Paulo, 2002.

MARTÍN-BARBERO, Jesús. Dos meios às mediações: comunicação, cultura e hegemonia. 2. ed. Rio de Janeiro: Editora da UFRJ, 2003.

MARTÍN-BARBERO, Jesús; REY, Germán. Os exercícios do ver: hegemonia audiovisual e ficção televisiva. São Paulo: Editora do Senac, 2001.

MIRA, Maria Celeste. O masculino e o feminino nas narrativas da cultura de massa ou o deslocamento do olhar. Cadernos Pagu, Campinas, SP, v. 21, p. 13-38, 2003.

MONNOT, Catherine. Petites filles d'aujourd'hui: l'apprentissage de la féminité. Coll Mutations, n. 251, Autrement, 2009.

MORIN, Edgar. Cultura e comunicação de massa. Rio de Janeiro: Fundação Getúlio Vargas, 1972a.

MORIN, Edgar. El Cine: o el Hombre Imaginário. Barcelona: Seix Barral, 1972b.

MORIN, Edgar. Cultura de massas no século XX: o espírito do tempo. Rio de Janeiro: Forense, 1975.

ODININO, Juliane. Super-Heroinas em Imagem e Ação: gênero, animação e imaginação infantil no cenário da globalização das culturas. 2009. 321f. Tese (Doutorado Interdisciplinar em Ciências Humanas) - Universidade Federal de Santa Catarina, Florianópolis, 2009.

ORTNER, Sherry. Making Gender: the politics and erotics of culture. Boston: Beacon Press, 1996.

PASSERINI, Luisa. Mulheres, consumo e cultura de massas. In: DUBY, George; PERROT, Michelle (Org.). Histórias das Mulheres no Ocidente. São Paulo: Ebratil, 1995. v. 5.

PINTO, Manuel; SARMENTO, Manuel. As Crianças: contextos e identidades. Lisboa: Bezerra, 1997. 
RADWAY, Janice. Reading the romance: women, patriarchy and popular literature. North Carolina: Chapel Hill, 1984.

RIAL, Carmen. Dez anos depois, revisitando "Japonês está para TV assim como mulatos para cerveja”: estereótipos raciais e étnicos na publicidade brasileira. In: WOLFF, Cristina Scheibe; FAVERI, Marlene de; RAMOS, Tânia Regina Oliveira (Org.). Leituras em rede: gênero e preconceito. Florianópolis, SC: Mulheres, 2007. p. 429-456.

SCOTT, Joan. Gênero: uma categoria Útil de Análise histórica. Educação e Realidade, Porto Alegre, v. 2, jul./dez. 1990.

ROCHA, Eloísa Acires Candal. A pesquisa em Educação Infantil: trajetória recente e perspectiva de consolidação de uma pedagogia da educação infantil. 1999. Tese (Doutorado em Educação) - Universidade Estadual de Campinas, Campinas, SP, 1999.

STAM, Robert; SHOAT, Ella. Crítica da imagem eurocêntrica: multiculturalismo e representação. Tradução de Marcos Soares. São Paulo: Cosac Naify, 2006.

STEINBERG, Shirley; KINCHELOE, Joe (Org.). Cultura infantil: a construção corporativa da infância. Tradução de George Bricio. 2. ed. Rio de Janeiro:

Civilização Brasileira, 2004. 


\section{"Powerpuff-girls in: the power of pink!?!?" For an understand- ing of childhood's femininity from media, gender and child- hood studies}

\section{Abstract}

This article discusses the social and cultural place of the girl, in the context of a globalized media culture. The analytical approach refers to surveys conducted with children of early grades from Florianopolis' metropolitan region in their school settings, and to the presence of identity references that culminate in the image we call "Powerpuff-girl". The analysis dialogues with, confronts and questions such representation, whose meanings are marked for their inherent ambiguity and contradiction, especially when appropriated and reinterpreted by children. Such an image brings together elements and features that go back to a kind of contemporary children's femininity, in which is possible to find more traditional cultural matrices. In this sense, some aspects related to women passivity and subservience appear alongside of more current characteristics related to women's achievements and the empowerment of women. For the research with children, we made use of ethnography and research of intervention in order to discuss power relations, especially those related to gender, childhood and media issues. As a result, we note that the children's femininity as much as they advanced towards equal rights and freedom of expression, are still occupying a place of subordination, of inferiority and naturalization of differences, being crystallized in sexist and discriminatory practices, which are experienced and reproduced daily in children's interrelations.

Keywords: Media. Childhood. Gender.
"Super-puissants-filles et le pink power!" Pour la compréhension de la féminité de I'enfance de l'étude des médias, de le genre et de I'enfance

\section{Résumé}

Cet article traite de la place sociale et culturelle de la jeune fille, dans le contexte d'une culture médiatique mondialisée. L'approche analytique se réfere à des enquêtes menées auprès des enfants dans les premières années, la région de la Florianópolis, avec des enfants d'âge scolaire et la présence de références identitaires qui culminent dans l'image que nous appelons Super-Fille-Pink. L'analyse des dialogues, des tensions et des questions telles la représentation, dont les significations sont marquées pour leur ambiguïté inhérente et la contradiction, surtout quand approprié par les enfants. Une telle image rassemble des éléments et caractéristiques qui remontent à une sorte de féminité des enfants contemporains, où vous pouvez trouver des matrices culturelles plus traditionnelles. En ce sens, inclure les aspects liés à la passivité et la soumission des femmes aux côtés des caractéristiques plus courants liés aux réalisations des femmes. Pour la recherche avec des enfants, nous avons utilisé de l'ethnographie et de recherche d'intervention avec objetiv de discuter des relations à pouvoir entre les sexes en particulier adaptés aux enjeux, les enfants et les médias. En conséquence, nous constatons que la féminité des enfants autant qu'il avança vers l'égalité des droits et la liberté d'expression, encore occupe toujours une place de subordination, d'infériorité et la naturalisation des différences, et cristallisé dans les pratiques sexistes et discriminatoires, qui Ils sont expérimentés et reproduits tout le temp dans les interrelations des enfants.

Mots-clés: Enfant. Genre. Medias. 
Juliane Di Paula Queiroz Odinino

E-mail: juodinino@gmail.com

Recebido em: 17/12/2014 Aprovado em: 18/7/2015 